\title{
Derivaciones del gran proyecto Puerto Norte en el barrio Refinería de la ciudad de Rosario, Argentina, 2001-2010
}

\author{
Gonzalo Martin Rodríguez y Beatriz Cuenya
}

Consejo Nacional de Investigaciones Cientificas y Técnicas, Argentina

Resumen

El trabajo intenta determinar si existió un proceso de gentrificación en el barrio Refinería (Rosario, Argentina) en el periodo 2001-2010 debido al impacto de la intensa renovación urbana a gran escala desarrollada en su inmediación conocida como proyecto Puerto Norte. El doble abordaje metodológico incluye técnicas cuali y cuantitativas, mediante un estudio de campo y el desarrollo de un índice de gentrificación que también es replicado al conjunto de la ciudad de Rosario. Se concluye que la gentrificación en Refinería ha sido por ahora leve e incipiente, principalmente debido a normativas que explícitamente han apuntado a contener la gentrificación del barrio preservando su perfil e identidad. Asimismo, el índice de gentrificación ha permitido detectar zonas de presumible gentrificación en diversos sectores de la ciudad que se distribuyen con un patrón espacial bien definido por fuera del área central.

Palabras clave: Gentrificación, renovación urbana, Puerto Norte.

Abstract

Derivations of Puerto Norte Project on the Refineria neighborhood of the city of Rosario, Argentina, 2001-2010

This paper aims to determine if gentrification happened in Refineria neighborhood (Rosario, Argentina) as a consequence of the urban renewal process known as Puerto Norte, developed in its proximities. A double cualitative and cuantitative aproach was used, including an intense field work and the development of an original statistical gentrification index applied both to Refinería and the whole city. The study concludes that some gentrification in Refinería did happen, but it is low and incipient, probably because of an urban legislation which was especially designed for containing large scale gentrification in the area, in order to preserve the neighborhood's profile and identity. The gentrification index also allowed to detect other zones of presumed gentrification in Rosario City, distributed in a well defined spatial pattern outside the central area.

Key words: Gentrification, urban renewal, Puerto Norte. 


\section{INTRODUCCION}

$\mathbf{E}$

1 presente trabajo pretende determinar si durante la primera década de este siglo comenzó a evidenciarse un proceso de gentrificación en el barrio Refinería de la ciudad de Rosario, debido a la implantación del gran proyecto urbano Puerto Norte en áreas aledañas. Siendo el barrio Refinería una zona residencial típica de clase media-baja, nuestra hipótesis es que podría haber experimentado el impacto de las grandes inversiones privadas y de las normativas públicas que dieron curso a Puerto Norte, considerado la intervención urbanística más importante en la historia de la ciudad. Este gran proyecto ha transformado tierras con previos usos ferro portuarios en una nueva centralidad que alberga modernos edificios para viviendas, oficinas, comercios y boutiques, gastronomía, hoteles, actividades culturales y otros usos de alta gama con la participación de inversores y usuarios de altos ingresos. El proyecto se inició en 1999 y se desarrolla en dos etapas desde hace más de 15 años. ${ }^{1}$

La estrategia metodológica definida para estudiar la gentrificación contempla un doble abordaje cuali-cuantitativo, a partir de diversas fuentes secundarias y primarias, y distintas escalas de observación. Luego de una introducción al concepto de gentrificación y al caso de estudio, se presenta un Índice de Gentrificación de tipo estadístico especialmente diseñado para este análisis. El índice es aplicado al conjunto de las subdivisiones censales que conforman la aglomeración Gran Rosario para el periodo 2001-2010, con el fin de identificar potenciales zonas de gentrificación, determinar si existe algún patrón espacial particular y si el Barrio Refinería puede ser tipificado como un área de gentrificación de acuerdo al índice. Los resultados obtenidos a partir de este enfoque se complementan y contrastan con los que surgen de un estudio previo realizado mediante un trabajo de campo en 2008. A través de registros y observaciones recogidas en algunos casos a nivel de manzanas y de parcelas, se indagaron distintos aspectos referidos a la dinámica del mercado inmobiliario, los usos del suelo y la construcción, buscando determinar el eventual impacto de Puerto Norte y la nueva normativa urbanística que se aplicó al barrio en el marco de la gestión de este gran emprendimiento.

${ }^{1}$ Las dos etapas de este gran proyecto reciben la denominación de Centro de Renovación Urbana Scalabrini Ortiz. Aunque Puerto Norte designa estrictamente a la segunda etapa, en este trabajo optamos por utilizar ese nombre para referirnos a ambas etapas por razones de simplificación; también porque la mayor envergadura de esta segunda etapa terminó por dejar en el olvido el nombre original. 


\section{LA GENTRIFICACION Y SUS INDICADORES}

El término gentrificación se emplea para referir a la dinámica de sustitución de estratos sociales bajos por altos en áreas centrales y pericentrales, generalmente vinculada a proyectos de renovación urbana y de revitalización de barrios. El término fue acuñado por la socióloga Ruth Glass (1964) al analizar el proceso de aburguesamiento de barrios obreros en Londres, cuyas modestas viviendas, al expirar sus alquileres se convertían una a una en residencias elegantes hasta desplazar a sus antiguos habitantes, cambiando por completo el carácter social del barrio.

Progresivamente, en sucesivos estudios, el concepto fue ampliando su contenido para dar cuenta de procesos de renovación urbana más recientes. Se incluyen acá los nuevos entornos construidos que, si bien no se implantan en distritos residenciales sino en espacios industriales en declinación, se convierten en la punta de lanza desde las cuales los tentáculos de la gentrificación se expanden lentamente hacia los vecindarios adyacentes (Davison and Lees, 2005 citado por Slater, 2006: 745). Asi, definiciones más actuales de la gentrificación se refieren a ella como "la producción del espacio por usuarios progresivamente más solventes" (Hackword, 2002 citado por Slater, 2003: 744). También se entiende por gentrificación las manifestaciones sociales y espaciales de una economía urbana industrial en transición a una pos industrial basada en las finanzas, los negocios y los servicios creativos, en asociación con cambios en la naturaleza y localización del trabajo, en la estructura ocupacional de las clases, en los ingresos y salarios, en los estilos de vida y en la estructura del mercado de la vivienda (Hamnett, 2003: 2402).

En todas las acepciones, está claro que la gentrificación alude a los impactos sociales y demográficos de los procesos de renovación de áreas centrales. Pero es además un fenómeno fisico-espacial, económico, político y cultural que resulta de múltiples causas. En tanto efecto de la reconfiguración del espacio urbano forma parte del largo y permanente proceso de reestructuración de la economía capitalista contemporánea. Desde el punto de vista de sus efectos, la gentrificación ha sido ampliamente cuestionada porque supone una canalización de los beneficios derivados del desarrollo urbano hacia los desarrolladores, empresarios y usuarios de clase media alta a expensas de la clase trabajadora y los grupos más pobres.

El estudio empírico de la gentrificación supone la operacionalización del concepto teórico general hasta arribar a una serie de indicadores a través de los cuales el fenómeno resulte susceptible de ser observado y, even- 
tualmente, sujeto a medición. En este sentido, distintos indicadores para el estudio de la gentrificación han sido propuestos en la literatura a lo largo de las últimas décadas, existiendo un importante grado de coincidencia entre los investigadores con respecto a la validez de los mismos (Butler y Lees, 2006; Herzer, 2008; Ley, 1986; Sandroni, 2006; Schaffer y Smith, 1986).

Un primer conjunto de indicadores son aquellos que buscan detectar cambios en la composición socioeconómica (o estatus social) de los barrios $^{2}$ : dentro de esta dimensión se analizan variables como el nivel de ingresos, el nivel educativo o el tipo de ocupación y calificación laboral de sus residentes. Una segunda clase de indicadores abarca los estrictamente demográficos (no referidos de modo directo al estatus social) como el aumento de los propietarios por sobre los inquilinos, la disminución del tamaño medio de los hogares y de la edad media de los jefes de hogar. El tercer conjunto de indicadores no refieren de manera directa a los habitantes sino a cambios en los usos del suelo y en el mercado inmobiliario en que éstos dirimen la localización de sus residencias: la evolución del precio del suelo y los alquileres, la cantidad de transacciones inmobiliarias, cambios en el calidad de diseño de las residencias (ya sea manteniendo su estilo edilicio cuando este connota una fuerte identidad patrimonial que se desea preservar, o bien, modificando el tipo de vivienda cuando se trata de estructuras edilicias modestas u obsoletas), y finalmente, la aparición de nuevos comercios y servicios más acordes a los hábitos de consumo de la clase media-alta (cafés de moda, bares, delicatessen, casas de diseño, clubes de fitness, spas, etc.).

Todos o casi todos estos indicadores pueden ser cuantificados, aun cuando ello no siempre ocurra en el marco de metodologías estrictamente estadísticas. De hecho, su cuantificación sirve generalmente de apoyo a estudios de caso más bien cualitativos sobre entidades espaciales de orden micro-local claramente identificadas. Sin embargo, algunos de estos indicadores también pueden servir para el desarrollo de algún tipo de índice estadístico que — por ejemplo a partir de datos censales - pueda ser replicado simultáneamente sobre una vasta cantidad de zonas, toda una ciudad o inclusive un conjunto de ciudades, con la finalidad de determinar en donde hubo o pudo haber habido gentrificación, cuál fue su intensidad, trazar tendencias y establecer comparaciones.

\footnotetext{
${ }^{2}$ Entendemos por barrio un espacio residencial de límites más o menos difusos pero subjetivamente significativos para sus habitantes. El concepto difiere radicalmente del de "zonas censales" que utilizaremos más adelante. Estas últimas son entidades espaciales arbitrariamente definidas y delimitadas (según criterios que difieren según el país) por los organismos censales y que pueden coincidir o no con otras entidades espaciales como los barrios.
} 


\section{El Caso de estudio}

\section{Puerto Norte y su contexto la ciudad de Rosario}

La aglomeración de Gran Rosario está ubicada a orillas del Río Paraná a 300 km del centro de la Ciudad de Buenos Aires, Capital de la República Argentina (Figura 1), con más de un millón 230 mil habitantes y una superficie aproximada de $291 \mathrm{~km}^{2}$ Rosario representa por su tamaño la tercera ciudad en importancia del país, después de las aglomeraciones de Gran Buenos Aires y Gran Córdoba.

Superada la profunda crisis económica que afectó a la Argentina durante 2001-2002, la ciudad de Rosario comenzó a experimentar un boom inmobiliario como no se veía desde la década de 1970 (Barenboim, 2013: 45). Se renovó la fisonomía urbana y edilicia en varios órdenes: mejora y creación de nuevos parques; incorporación de equipamientos culturales, deportivos y hospitalarios; construcción de avenidas y vías de acceso; montaje de grandes centros comerciales y proliferación de nuevos bares, restaurantes y comercios en el centro y frente a la costa; rehabilitación de edificios de valor patrimonial que refuerzan la revalorización del centro, y puesta en marcha de grandes operaciones de renovación urbana, como la creación de la nueva centralidad de Puerto Norte.

En la base de la importante renovación urbanística existe una mutación en la estructura económica de Rosario. Sin abandonar sus actividades portuarias e industriales, la ciudad comenzó a consolidar su perfil como centro de servicios, en el cual se fueron expandiendo los servicios ligados a las empresas culturales, exposiciones y eventos, y al turismo de alcance internacional. De manera complementaria, se registró la afluencia de capital inmobiliario, motorizado tanto por desarrolladores internacionales como por actores económicos locales beneficiarios de la política económica nacional impulsada desde 2003; estos últimos incluyen sectores ligados al campo y a la industria, así como profesionales independientes que demandan propiedades de alta gama para vivir pero también como alternativa de inversión y de ahorro a futuro. También influyó en el proceso de reactivación inmobiliaria de Rosario la culminación en 2003 del puente que une esta ciudad con la vecina Victoria en la Provincia de Entre Ríos, cruzando el Río Paraná. Todo esto contribuyó a un crecimiento sostenido de la construcción que ocurrió pese a los costos crecientes. 


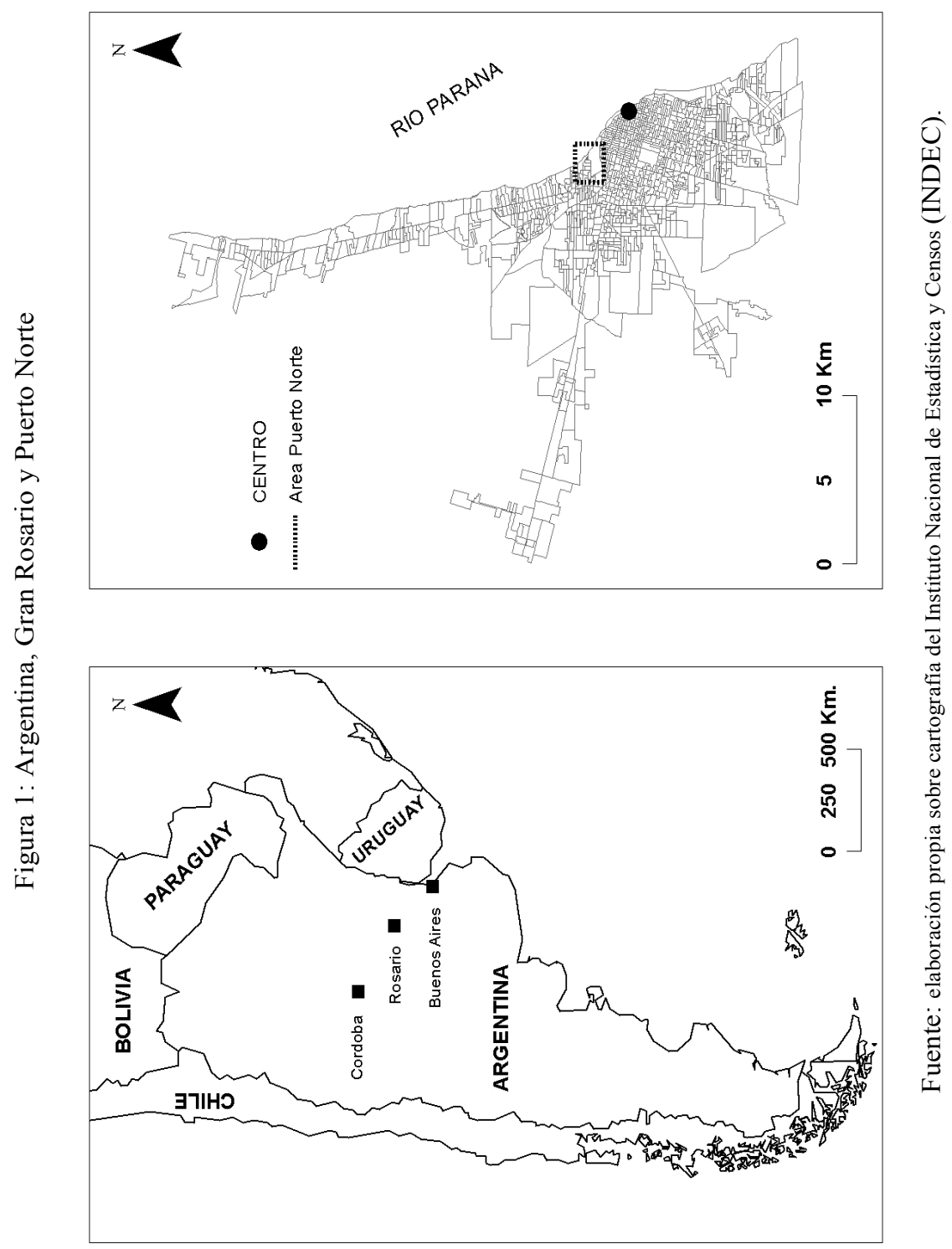


La mejora en el mercado de propiedades no fue sólo cuantitativa sino cualitativa: el aumento en el poder adquisitivo de los nuevos inversores favoreció la incorporación de mejores características de confort a la oferta inmobiliaria con edificios con piscina, amplios estacionamientos y variedad de servicios centrales (Cuenya, González, Mosto y Pupareli, 2012).

En este contexto comenzó a desarrollarse el gran proyecto urbano Puerto Norte (Figura 1) cuya ejecución en dos fases lleva ya más de 15 años, encontrándose actualmente (2017) en sus tramos finales. El perímetro del proyecto comprende unas 100 hectáreas de tierras desafectadas de sus previos usos ferro-portuarios.

La primera fase del proyecto comenzó a efectivizarse en 1999 con la construcción del centro comercial Alto Rosario (inaugurado en 2004) ${ }^{3}$ y el Parque Scalabrini Ortiz. Esta primera fase también contempló un sector destinado a condominios, torres y hotel cinco estrellas, pero su desarrollo fue mucho más tardío.

La segunda etapa se inició en 2004 a partir de un Concurso Nacional de Ideas lanzado por el municipio, y que se tradujo un año más tarde en el Plan Especial de Puerto Norte. Mediante una ordenanza básica se definieron los trazados estructurales, los espacios públicos, las normas de parcelamiento del suelo, las áreas de preservación histórica y se establecieron los procedimientos generales para llevar adelante la urbanización integral del proyecto. Para esta segunda fase, el conjunto del área de Puerto Norte fue subdividida en siete zonas o unidades de gestión, en función de la diversidad de situaciones en cuanto a la propiedad de la tierra o de las diferentes modalidades de organización entre propietarios. Gradualmente, mediante convenios específicos con los respectivos propietarios-desarrolladores de cada unidad de gestión, se fueron aprobando los planes de detalle que establecieron los tipos de usos y el perfil morfológico de cada sector.

En su conjunto Puerto Norte contempla la construcción de modernos edificios para viviendas, oficinas, comercios y boutiques, gastronomía, hoteles y actividades culturales y náuticas. ${ }^{4}$ Algunos de estos usos se montaron sobre viejas instalaciones industriales, obsoletas pero de singular valor patrimonial. El proyecto también destinó 42 hectáreas de suelo para uso público incluyendo espacios de circulación y áreas verdes ubicadas en el borde de la barranca del Río Paraná.

\footnotetext{
${ }^{3}$ Estos emprendimientos se realizaron en tierras del Estado Nacional, vendidas al propietario de una cadena nacional de supermercados y a la principal firma desarrolladora de centros comerciales en el país (IRSA Inversiones y Representaciones SA).

${ }^{4}$ El Plan Especial de Puerto Norte fijó los lineamientos generales de uso del suelo, trazados públicos, espacios verdes y densidades en cada una de los ocho sectores en que fue dividida el área, también llamadas Unidades de Gestión.
} 
Contribuyó asimismo a mejorar la accesibilidad, al favorecer la conectividad entre el centro y las zonas norte y oeste de la ciudad. Con una ubicación estratégica, dada su proximidad al centro urbano y su extenso frente sobre el río Paraná, Puerto Norte alberga una demanda de alto poder adquisitivo integrada por empresas, inversores y usuarios que operan en el ámbito local, nacional e internacional.

A los fines de la presente investigación es importante tener en cuenta que al realizarse el último censo nacional en octubre de 2010 apenas se encontraba efectivamente ocupada una pequeña parte del nuevo parque habitacional (torres y condominios) correspondientes tanto a la fase 1 como a la fase 2 .

\section{El barrio Refinería: orígenes y perfil en 2001}

El barrio Refinería (Figura 2) se ubica a unos cuatro $\mathrm{km}$ al norte del Centro Cívico de la ciudad, ocupando una superficie de aproximadamente 100 hectáreas, "envueltas" por el área de actuación de Puerto Norte, por lo que se lo considera pasible de recibir los impactos propios de esta clase de megaproyectos: el aumento real y/o la expectativa de aumento en los precios del suelo, la renovación edilicia (reemplazo de usos existentes por usos jerárquicos, aumento de densidades e índices de construcción, etc.), la llegada de usuarios de altos ingresos y el desplazamiento de los residentes de menores recursos previamente localizados en el área. El perfil de este barrio refuerza la presunción de gentrificación ya que se trata de un barrio de origen obrero.

Refinería surgió a mediados del siglo XIX a partir de la instalación de un saladero y una refinería de azúcar a la cual debe su nombre. Con el tiempo se transformó en uno de los barrios obreros más populosos, en el que también residen sectores de clase media. Desde sus orígenes, el barrio estuvo limitado por las enrieladuras de vías de acceso al puerto y las industrias e instalaciones de acopio de granos vinculadas al comercio fluvial y marítimo, aunque estas barreras urbanas se fueron eliminando a lo largo del último siglo gracias a diferentes obras viales que permitieron mejorar la conexión del barrio con el resto de la ciudad. ${ }^{5}$ La contaminación ambiental generada por el transporte de granos que circulaban por sus calles hacia las industrias del entorno así como por el uso de pesticidas industriales, durante muchas décadas afectó la salud de sus moradores.

\footnotetext{
${ }^{5}$ En un principio el barrio estaba delimitado, al Sur y Oeste por las vías y talleres del F.C. Central Argentino, el arroyo Ludueña al Norte y desde los muelles de embarque hacia el Oeste. En la actualidad el Barrio Refinería (identificado en el Código Urbano como Distrito E1) está delimitado por Av. Tres Vías, el río, calle Junín y Bv. Avellaneda.
} 
Derivaciones del gran proyecto Puerto Norte en el barrio Refinería ... /G. M. RODRÍGUEZ y B. CUENYA

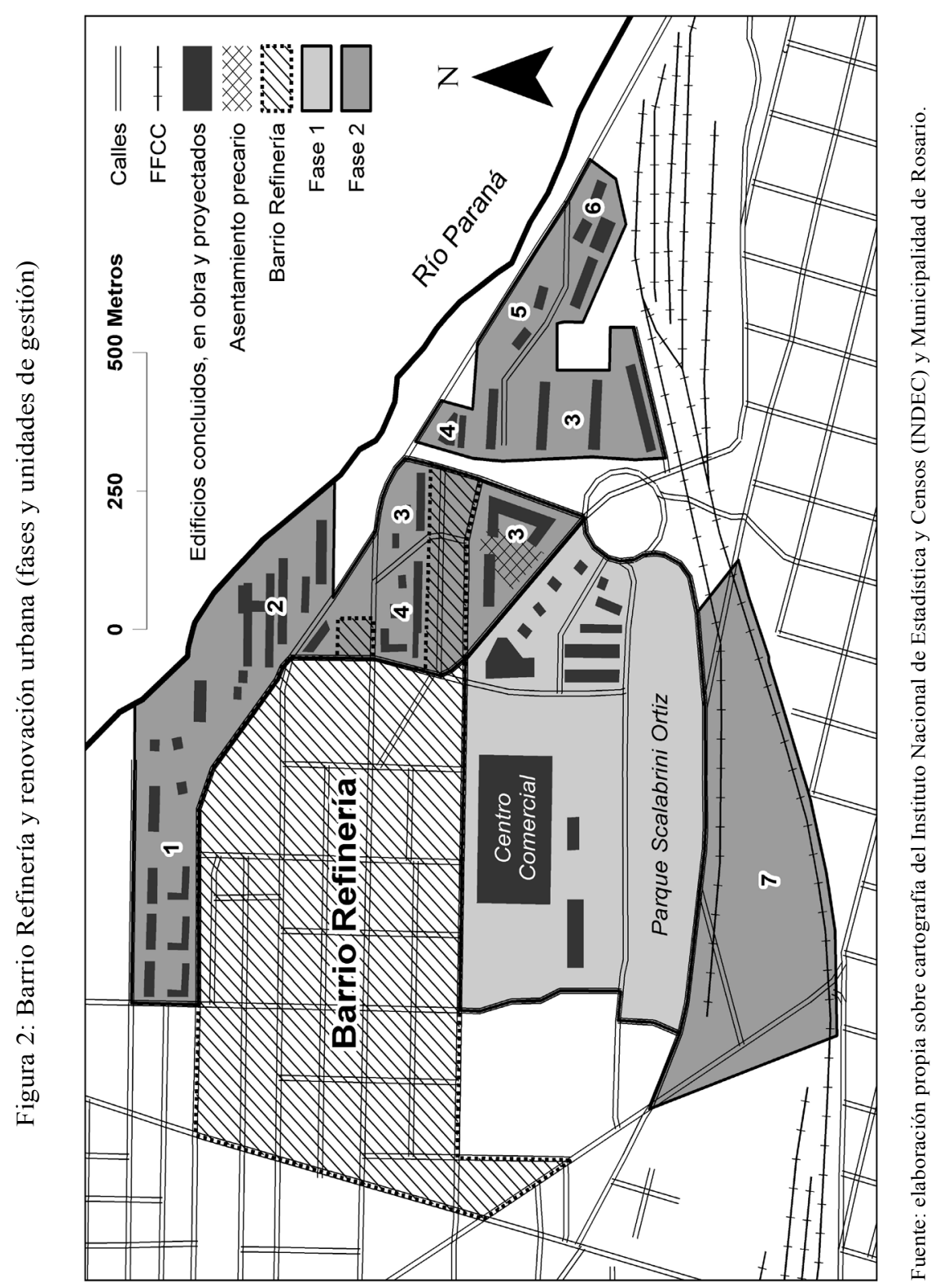


Recién en la década de 1990 se mejoró la situación gracias al levantamiento de las industrias contaminantes en la ribera.

De acuerdo al censo de 2001 habitaban el barrio aproximadamente 4 500 personas, con una promedio que varía entre 150 y 200 habitantes por manzana. El 75 por ciento de los hogares era propietario de sus inmuebles, predominado viviendas unifamiliares habitadas por terceras y cuartas generaciones de familias obreras. Las viviendas presentaban regular a buen estado de conservación y 91 por ciento de los hogares habitan en casas sin hacinamiento (es decir, con menos de dos personas por habitación). Los indicadores ocupacionales indicaban la presencia de un grupo social estable, de estrato medio/bajo. El uso predominante era y sigue siendo la residencia, encontrándose ocupadas entre 75 y 100 por ciento de las parcelas según manzana. La antigüedad edilicia promedio rondaba los 48 años.

\section{Nueva normativa para el barrio Refinería en 2005}

El sector residencial del barrio Refinería y la primera fase de Puerto Norte no se superponían originalmente en sus límites. Sin embargo, en el marco de la segunda fase la Ordenanza 7892 de 2005 se impuso una división del barrio en dos sectores, a cada uno de cuales se les aplicó una normativa distinta, con impactos presumiblemente diferentes en cuanto a la gentrificación.

En la planificación y diseño de los grandes proyectos urbanos la relación de éstos con sus contextos inmediatos no suele ser un tema prioritario (Kozak y Feld, 2015). Sin embargo, esto no parece haber ocurrido en el caso de Puerto Norte. A un primer sector conformado por el grueso del barrio, compuesto por 32 manzanas de lotes regulares pequeños, ocupados por depósitos y viviendas modestas, se lo mantuvo como Distrito E1-1 (según la nomenclatura del Código Urbano) y se le fijó además una disminución de los índices urbanísticos y edilicios ${ }^{6}$ con el propósito explícito de preservar el perfil del barrio evitando el avance de las inversiones inmobiliarias sobre el mismo, especialmente la edificación en torres. En palabras del entonces funcionario a cargo de la Secretaría de Planeamiento "Muchas ciudades que renovaron espacios urbanos destruyeron lo que había y terminaron expulsando a sus habitantes. Queremos facilitar una renovación del barrio pero con casas y construcciones como las que hay ahora" (Declaraciones

\footnotetext{
${ }^{6}$ Los predios correspondientes al Distrito Urbano E1-1 tienen los siguientes indicadores urbanísticos particulares: No se permiten subdivisiones pero sí unificación de lotes. Índice edilicio máximo de 1. Índice edilicio mínimo de 0.33. Altura máxima de Planta baja y un piso. Altura máxima sobre avenidas de 30 metros, correspondiente a una planta baja y nueve pisos altos. No se permite la construcción de edificios en torre. Se admiten los usos generales estipulados para los Distritos E1, salvo Industrias y Depósitos.
} 


\section{Derivaciones del gran proyecto Puerto Norte en el barrio Refinería ... /G. M. RODRÍGUEZ y B. CUENYA}

de M. Levin al periódico El Ciudadano, 18 de agosto de 2005. Citado en Cuenya y Pupareli, 2006)

Pero el segundo sector, más pequeño y de aproximadamente cuatro hectáreas, quedó de alguna forma incluido dentro del área de renovación urbana de Puerto Norte (ver área rayada sobre la Unidad de Gestión 4 en la Figura 2) siéndole aplicada en adelante la normativa de renovación urbana correspondiente a dicho distrito. Este pequeño sector se compone a su vez de dos sub sectores. Por un lado, un terreno de una hectárea cuyo propietario muy pronto acordó con el municipio nuevos indicadores urbanos en el marco de la normativa específica que regula las urbanizaciones integrales y que habilitan la construcción de edificios en altura. Por otro lado, sesenta lotes menores cuyos habitantes originalmente se asentaron allí de manera irregular pero que en su mayoría fueron regularizados a través del llamado Plan Arraigo en 1992. Por sus características socio demográficas (escasos propietarios, hogares en situación de pobreza, etc.) y normativas edilicias más permisivas respecto a la renovación urbana, es probable que este sector se presente como el más vulnerable a sufrir un proceso de gentrificación.

\section{UN ÍNDICE ESTADÍSTICO DE GENTRIFICACIÓN}

El interés de estudiar la gentrificación a través de un índice estadístico radica en su potencialidad de ser replicado simultáneamente sobre una vasta cantidad de zonas, incluso toda una ciudad o conjunto de ciudades, con la finalidad de determinar adónde hubo o puede haber habido gentrificación y cuál fue su intensidad.

En la literatura especializada existe un único antecedente respecto al uso de índices de gentrificación. Se trata del desarrollado por David Ley (1986) para ser aplicado sobre 22 ciudades canadienses con el fin de someter a prueba distintas hipótesis explicativas de la gentrificación. Para cada zona censal de cada ciudad Ley construyó primero un índice de estatus social, al que definió como el promedio de dos porcentajes: el de mano de obra empleada en el sector cuaternario (profesionales, gerentes, técnicos $\mathrm{y}$ administrativos) y el de población con nivel de estudios universitarios completos. Luego, el índice de gentrificación se calcula simplemente a partir de la diferencia entre el índice de estatus social medido para un año inicial y otro para el final del periodo: hay gentrificación si la diferencia es positiva (es decir, donde quiera que el estatus social de una zona haya mejorado) y no la hay si la diferencia es negativa o se mantiene igual.

El índice de gentrificación que aquí proponemos difiere del de Ley por su mayor complejidad. Para su construcción partimos de la respuesta a 
tres interrogantes fundamentales: i) ¿qué variable de segmentación social utilizar para identificar a los grupos sociales involucrados en la gentrificación (desplazados y gentrificadores); ii) ¿qué criterios fijar para identificar aquellas zonas potencialmente expuestas a gentrificación, llámense barrio obrero, popular, de clase trabajadora u otra denominación?; y iii) ¿qué alteraciones relevantes considerar que deben producirse en la composición socioeconómica de cada zona a través del tiempo para hablar de gentrificación?

En relación al primer interrogante procedemos a segmentar socioeconómicamente a los hogares de la ciudad según el nivel de educación completado por el jefe o jefa de hogar. ${ }^{7}$ Se sabe que el nivel de educación mantiene una relación estrecha con el estatus social y el poder adquisitivo y, en última instancia, con las diferentes oportunidades que tienen los hogares de acceder a y permanecer en las distintas localizaciones dentro de la ciudad (cuestión vital cuando tratamos de gentrificación). A partir de esta variable se establece una clasificación dicotómica, exhaustiva y excluyente, de los hogares de la ciudad de Rosario en dos grandes grupos: nivel socioeconómico bajo (NSB) y nivel socioeconómico alto (NSA) ${ }^{8}$ Respecto al segundo interrogante podríamos identificar —en principiocomo potencialmente expuestas a gentrificación todas aquellas zonas cuya composición era mayoritariamente de nivel socioeconómico bajo (NSB) al inicio del periodo, 2001. En relación al tercer interrogante y continuando con la lógica anterior, se podría simplemente postular que hubo gentrificación en toda aquella zona donde el grupo NSB era mayoría en 2001 y dejó de serlo en 2010.

Esta primera aproximación general necesita, sin embargo, ser precisada y ajustada en base a una serie de consideraciones. Por un lado, existe el problema de que el paso de NSB $>50$ por ciento en 2001 a NSB $<50$ por ciento en 2010 puede ser el resultado de cambios estadísticamente insignificantes tanto en términos absolutos como relativos. Por ejemplo, estaríamos identificando como potencialmente gentrificada una zona que pasó de tener 101 hogares NSB (50.5 por ciento) y 100 hogares NSA (49.5 por ciento) en 2001, a tener 100 hogares NSB (49.5 por ciento) y 101 hogares NSA (50.5 por ciento) en 2010. De esta manera y para prevenir calificar

\footnotetext{
${ }^{7}$ Los censos argentinos no relevan información sobre nivel de ingresos. Por su parte, los microdatos sobre categoría ocupacional, nivel de calificación, rama de actividad etc. no se encuentran disponibles para el año 2010.

${ }^{8}$ El grupo NSB incluye a todos aquellos jefes de hogar comprendidos en el rango que va desde "sin instrucción", hasta "nivel secundario incompleto"; el grupo NSA por su parte abarca los hogares cuyo jefe cuenta con un nivel de instrucción que va desde "secundario completo" hasta "universitario completo".
} 


\section{Derivaciones del gran proyecto Puerto Norte en el barrio Refinería ... /G. M. RODRÍGUEZ y B. CUENYA}

como presumiblemente gentrificada una zona que experimentó esta clase de cambios decidimos adoptar un parámetro de al menos diez puntos porcentuales de diferencia entre el porcentaje de hogares NSB en 2001 y su porcentaje en $2010 .^{9}$

En segundo lugar, existe el problema de que una disminución de hogares NSB a lo largo del periodo no necesariamente ha de interpretarse como la consecuencia de un desplazamiento de hogares NSB y su reemplazo por hogares NSA. En Rosario - igual que en el resto del país - existe históricamente una tendencia a la mejora en el nivel educativo de los jefes de hogar. Parece lógico, entonces, que los cambios en la composición socioeconómica de los habitantes de cada zona sean interpretados en el contexto más amplio de los cambios producidos en la ciudad en su conjunto (Rubiales Pérez, 2014: 5-6). Para lidiar con este problema se propone calcular para cada zona de la ciudad un Índice de Variación Relativa (IVR) de los hogares NSB, que se define como la variación relativa del grupo NSB en cada zona, dividida por la variación relativa del grupo NSB en la ciudad en su conjunto. De esta manera:

- Si IVR es $<0$, la cantidad de hogares NSB varió en sentido contrario al conjunto de la ciudad.

- $\quad$ Si IVR es $>0$ y $<1$, la cantidad de hogares NSB varió en el mismo sentido que el conjunto de la ciudad, pero por debajo de la media urbana.

- $\quad$ Si IVR es = 1, la cantidad de hogares NSB varió igual que la ciudad.

- Y finalmente, si IVR es $>1$, la cantidad de hogares NSB varió en el mismo sentido y por encima del nivel de la ciudad (Figura 3).

La interpretación definitiva del IVR en términos de gentrificación para cada zona dependerá, por supuesto, de lo ocurrido con el grupo en el conjunto de la ciudad. En Rosario, y dado que la cantidad de hogares NSB se redujo (Tabla 1) el valor compatible con un proceso de gentrificación será un IVR mayor que 1 (disminución de hogares NSB mayor a la media urbana)..$^{10}$

El índice de gentrificación propuesto se construye finalmente a partir del cumplimiento de una serie de condiciones lógicas relacionadas a los tres interrogantes que planteamos más arriba.

\footnotetext{
${ }^{9}$ Por ejemplo, de 55 por ciento en 2001 a 45 por ciento en 2010 ; o de 59 a 49 por ciento.

${ }^{10}$ Por el contrario, si los hogares NSB hubieran aumentado su porcentaje en la ciudad, el valor de IVR compatible con un proceso de gentrificación sería uno menor que 0 (disminución de la cantidad de hogares NSB en la zona analizada).
} 


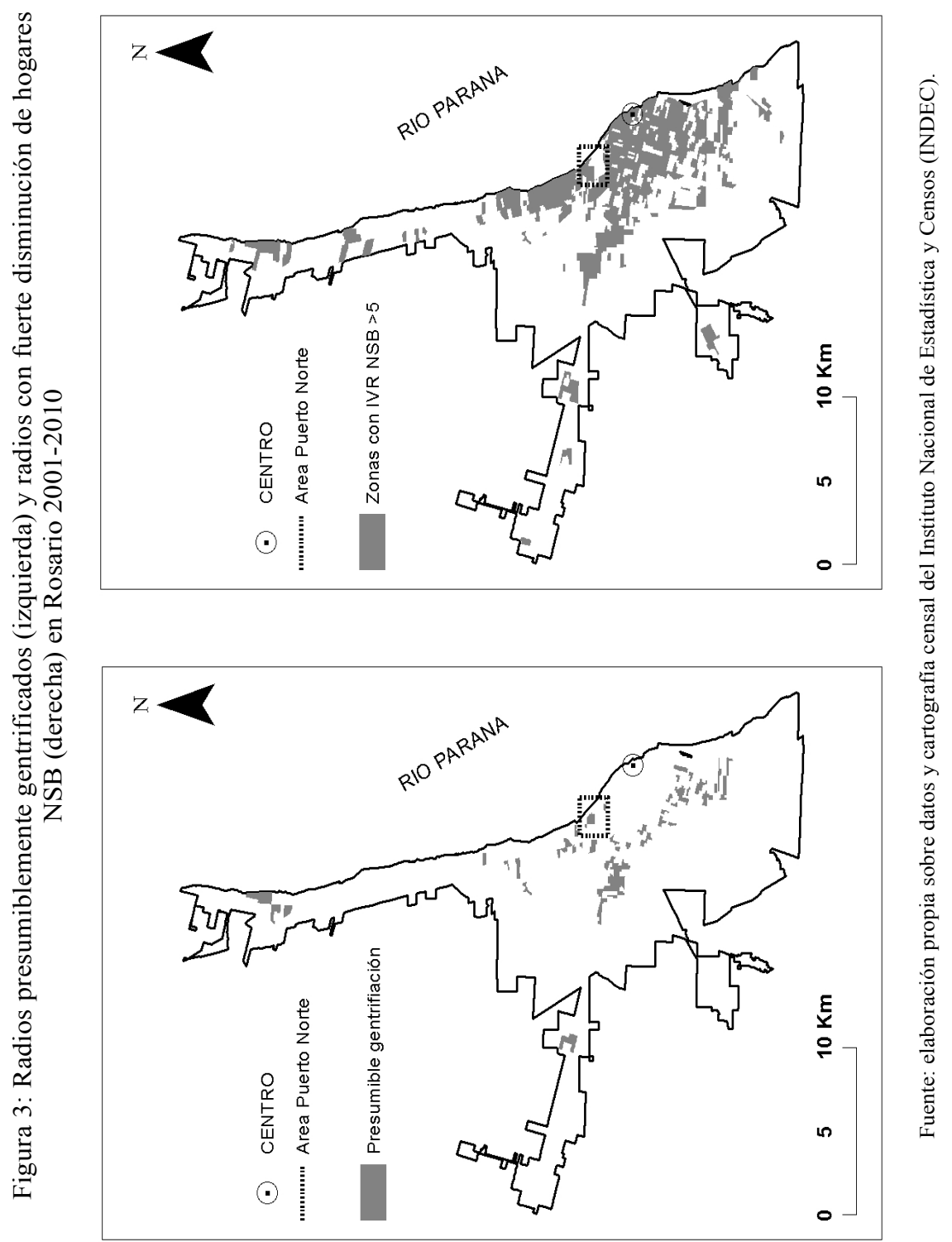


Tabla 1: Evolución de indicadores de gentrificación en Gran Rosario, 2001-2010

\begin{tabular}{lrrrr}
\hline & \multicolumn{2}{c}{ Cantidad } & \multicolumn{2}{c}{ Variación } \\
\hline & 2001 & 2010 & Absoluta & Relativa \\
\hline Nivel socioeconómico de los hogares & & & & \\
Bajo (NSB) & 214690 & 209.218 & -5.472 & $-2.5 \%$ \\
Alto (NSA) & $63 \%$ & $52 \%$ & & \\
& 128072 & 191.947 & 63.875 & $49.9 \%$ \\
Total & $37 \%$ & $48 \%$ & & \\
Regimen de tenencia del inmueble & 342762 & 401.165 & 58.403 & $17.0 \%$ \\
Propietarios de la vivienda y terreno & $100 \%$ & $100 \%$ & & \\
& 245927 & 274.077 & 28.150 & $11.4 \%$ \\
Propietarios sólo de la vivienda & $72 \%$ & $68 \%$ & & \\
Inquilinos & 15439 & 20.532 & 5.093 & $33.0 \%$ \\
Otras formas de tenencia & $5 \%$ & $5 \%$ & & \\
Total & 40579 & 68.763 & 28.184 & $69.5 \%$ \\
Edad de los jefes de hogar & $12 \%$ & $17 \%$ & & \\
Promedio años & 40773 & 41.166 & 393 & $1.0 \%$ \\
Tamaño de los hogares & $12 \%$ & $10 \%$ & & \\
Promedio miembros & 342718 & 404.538 & 61.820 & $18.0 \%$ \\
\hline Fuente & $100 \%$ & $100 \%$ & & \\
& 5 & & & \\
& 51.2 & 50.1 & -1.15 & $-2.3 \%$ \\
& 3.4 & 3.0 & -0.38 & $-11.1 \%$ \\
\hline
\end{tabular}

Fuente: elaboración propia en base a datos del Instituto Nacional de Estadística y Censos (INDEC).

Concretamente, se postulará la existencia de posible gentrificación en aquellos radios censales ${ }^{11}$ de la aglomeración Gran Rosario donde se cumplan simultáneamente las siguientes condiciones:

\section{Condición 1}

El grupo de nivel socioeconómico bajo (NSB) era mayoritario (51 por ciento o más) en 2001 y minoritario (49 por ciento o menos) en 2010, siendo además la brecha entre ambos porcentajes igual o mayor a 11.5

${ }^{11}$ Los radios censales son el máximo nivel de desagregación espacial para el que se reportan datos de los censos 2001 y 2010 en Argentina. Son delimitados exclusivamente bajo el criterio de facilitar el operativo censal y contener aproximadamente 300 viviendas. Sus límites no suelen alterarse con el tiempo, salvo por subdivisión. Para asegurar la compatibilidad de la cartografía censal de ambos años, todos aquellos radios subdivididos en 2010 fueron restituidos (combinados) a sus anteriores límites de 2001. 
puntos (considerando que fue de 11 puntos porcentuales en el conjunto de Rosario, ver Tabla 1).

\section{Condición 2}

a) La cantidad absoluta de hogares NSB disminuyó cinco o más veces en relación a la disminución ocurrida en el conjunto de Rosario (Índice de variación relativa IVR $>5$ ).

b) La cantidad de hogares con nivel socioeconómico alto (NSA) creció diez por ciento o más en relación a 2001.

\section{Condición 3}

La cantidad total de hogares en el radio censal es mayor a cien, tanto en 2001 como en 2010.

La condición 1 permite una primera identificación de los radios censales posiblemente gentrificados. La condición 2 previene identificar gentrificación en radios donde el cumplimiento de la condición 1 sea consecuencia de i) posibles desplazamientos de NSB sin reemplazos por NSA, o ii) aumentos significativos de NSA sin desplazamientos de NSB. Por último, la condición 3 es sólo accesoria y permite dotar nuestros análisis de un nivel aceptable de significancia estadística. ${ }^{12}$

Adicionalmente a lo que exprese el índice, observaremos asimismo el comportamiento de otra serie de indicadores complementarios, comúnmente referidos en la literatura especializada como indicadores de gentrificación. No los consideramos por sí mismos suficientes ni necesarios, pero en la medida que se verifiquen pueden contribuir a complementar y enriquecer la interpretación de los resultados obtenidos a partir del índice y el trabajo de campo. Refieren a cambios en el régimen de tenencia, la edad promedio de los jefes de hogar y el tamaño promedio de los hogares. Para cada una de estas variables se calcula también un índice de variación relativa, a fin de poder interpretar su comportamiento en cada radio censal en relación a lo ocurrido en el conjunto urbano (Tabla 1). De esta manera, serían compatibles con procesos de gentrificación en las zonas analizadas de Rosario:

- Un aumento de propietarios, más intenso que el registrado en la ciudad.

${ }^{12}$ En toda la aglomeración de Rosario hay sólo 11 radios censales que no cumplen esta tercera condición. 
- Una disminución absoluta de los inquilinos; o incluso un aumento siempre y cuando sea menor al aumento registrado en la ciudad.

- Una disminución de la edad promedio de los jefes mayor a la registrada en la ciudad.

- Una disminución del tamaño promedio de los hogares mayor que la registrada en la ciudad.

\section{INDICIOS ESTADISTICOS DE GENTRIFICACION EN ROSARIO Y REFINERÍA}

\section{Cambios socioeconómicos y demográficos en el Gran Rosario 2001-2010}

Antes de presentar los resultados que arroja el índice de gentrificación conviene repasar brevemente algunos cambios socioeconómicos y demográficos ocurridos en la aglomeración Gran Rosario (Tabla 1). Como ya hemos argumentado, esto es importante para situar en su contexto e interpretar correctamente las transformaciones acaecidas en cada zona específica de la ciudad. Por lo demás, parte de esta información es la que se ha introducido como parámetros para el cálculo de los índices de variación relativa (IVR), y de allí, a la identificación de zonas presumiblemente gentrificadas.

Un aspecto a destacar es que se repite en Rosario la misma tendencia que en el país relacionada a la movilidad educativa ascendente de los jefes de hogar: 63875 nuevos hogares se incorporaron a la categoría NSA, pasando de representar 37 por ciento en 2001 a 48 por ciento en 2010 (11 puntos porcentuales); ${ }^{13}$ los hogares NSB en cambio no sólo redujeron su peso relativo de 63 a 52 por ciento, sino también su cantidad absoluta (-5.472).

Respecto a los indicadores complementarios podemos observar lo siguiente. La información sobre régimen de tenencia de las viviendas muestra que la cantidad de propietarios aumentó en un 11.4 por ciento, aunque su peso relativo disminuyó, principalmente en virtud del significativo aumento de las relaciones de alquiler: la cantidad de inquilinos creció casi 70 por ciento. Por su parte, tanto la edad promedio de los jefes de hogar como la cantidad promedio de personas por hogar se redujeron de 51.2 a 50.1 años la primera, y de 3.4 a 3.0 miembros la segunda. Visto así, el comportamiento de casi todos los indicadores - excepto el importante aumento de inquilinos - sería compatible con el esperado en un proceso de gen-

\footnotetext{
${ }^{13}$ Estos datos no deben interpretarse necesariamente como hogares cuyos jefes mejoraron su nivel educativo. Más bien, es probable que en la mayoría de los casos se trate de nuevos jefes de hogar, jóvenes con mejor nivel educativo que — habiendo dejado el hogar materno- ingresaron a dicha categoría durante la última década.
} 
trificación; será importante tener esto en cuenta al examinar qué ocurrió específicamente en cada zona.

\section{Identificación de zonas presumiblemente gentrificadas en Gran Rosario}

Del mosaico de 1076 radios censales que componen la aglomeración Gran Rosario, 109 han sido identificados por nuestro índice como zonas donde puede haber ocurrido gentrificación durante el periodo 2001-2010. Estos 109 radios cumplen las tres condiciones especificadas en la construcción del índice: i) porcentaje de hogares NSB mayor a 51 por ciento en $2001 \mathrm{y}$ menor a 49 por ciento en 2010 siendo la brecha entre ambos porcentajes mayor a 11.5 puntos; ii) una disminución de hogares NSB como mínimo cinco veces mayor a la ocurrida en el conjunto de Rosario, con un aumento de hogares NSA de como mínimo diez por ciento en relación a 2001; y iii) cantidad de hogares mayor a 100 en 2001 y 2010. La distribución espacial de estos 109 radios se analiza a continuación en función de su distancia al Centro Cívico de Rosario (Tabla 2).

Tabla 2: Radios censales presumiblemente gentrificados según distancia al centro de la ciudad

\begin{tabular}{lrrrrrr}
\hline \multicolumn{7}{c}{ Distancia al centro (kilómetros) } \\
\hline & 0 a 2.5 & 2.6 a 5.0 & 5.1 a 7.5 & 7.6 a 10 & más 10 & Total \\
\hline Radios & 0 & 45 & 41 & 11 & 12 & 109 \\
gentrificados & $0 \%$ & $41 \%$ & $38 \%$ & $10 \%$ & $11 \%$ & $100 \%$ \\
\hline $\begin{array}{l}\text { Fuente: elaboración propia sobre datos y cartografía censal del Instituto Nacional de Estadística y Censos } \\
\text { (INDEC). }\end{array}$
\end{tabular}

La distribución espacial de los 109 radios presumiblemente gentrificados es sugestiva. permitiendo detectar a simple vista un patrón bien definido en forma de anillo alrededor del área central (Figura 4). Ninguno de los radios presumiblemente gentrificados se localiza en el área central, encontrándose a $2.7 \mathrm{~km}$ el más próximo. Una parte importante de estos radios (41 por ciento) se localizan a una distancia de entre $2.6 \mathrm{~km}$ y $5 \mathrm{~km}$ del centro.

Sin embargo, nótese que la gran mayoría de los radios céntricos presentan índices de variación relativa (IVR) de hogares NSB bastante elevados. Si nuestro índice no los identifica como presumiblemente gentrificados, es porque el porcentaje de hogares NSB no era en ellos mayor a 50 por ciento en 2001 (es decir, no cumplen la condición 1). 
Derivaciones del gran proyecto Puerto Norte en el barrio Refinería ... /G. M. RODRÍGUEZ y B. CUENYA

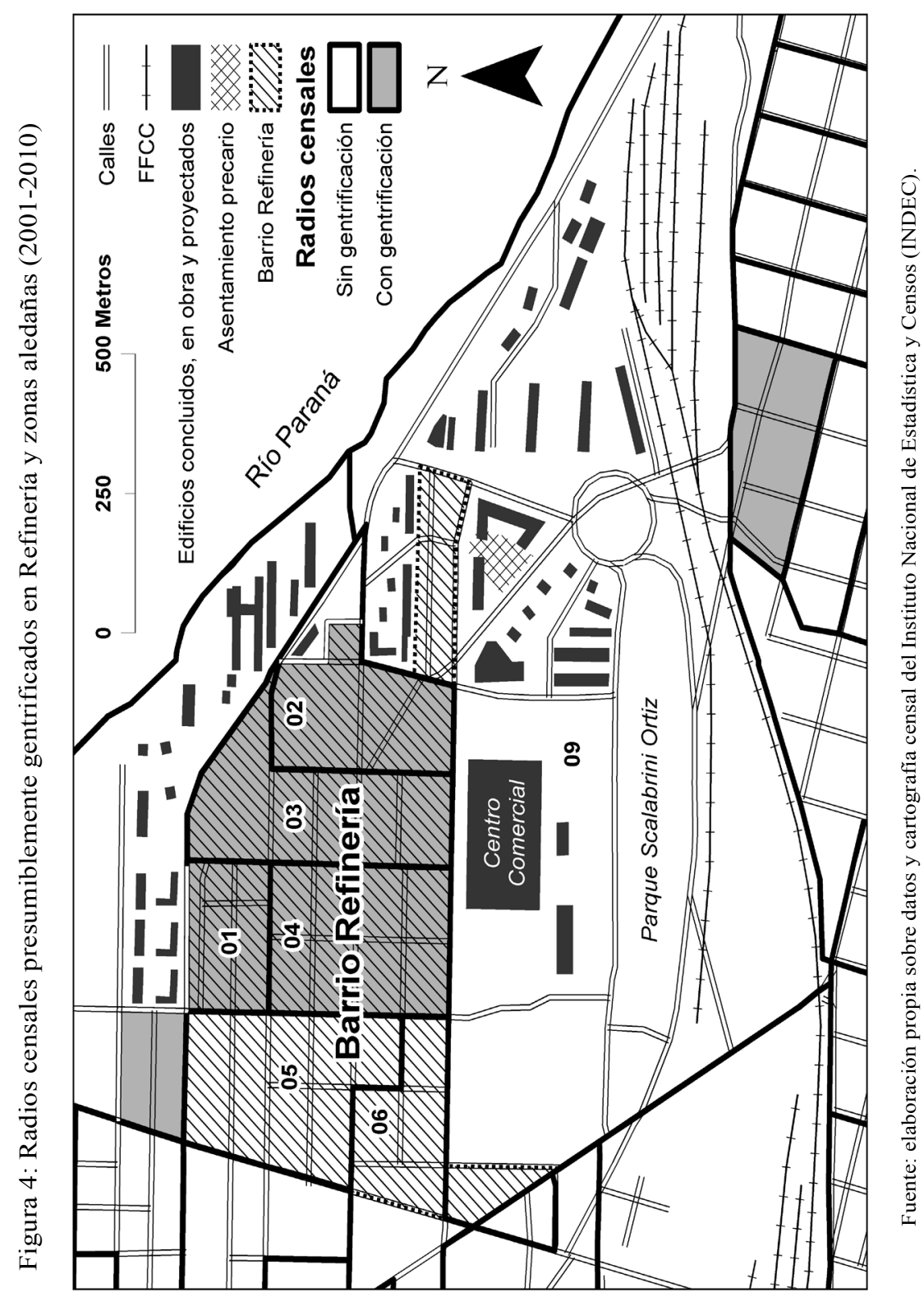




\section{Identificación de zonas presumiblemente gentrificadas en el Barrio Refinería}

El barrio Refinería se encuentra contenido por un mosaico de siete radios censales $(01,02,03,04,05,06$ y 09) correspondientes a la Fracción censal 15 del Departamento 084 (Rosario). Antes de presentar los índices de gentrificación por radio censal es oportuno hacer algunas aclaraciones metodológicas, que tienen que ver básicamente con que aquella entidad a la que en términos estrictamente censales designamos como Refinería, es en realidad una aproximación por exceso — aunque aceptable — de la entidad real, el "barrio" y sus límites según sus vecinos.

Los radios 03, 04 y 05 son los únicos totalmente comprendidos en el perímetro del barrio propiamente dicho, y lo mismo podría decirse del radio 02, ya que si bien incluye una pequeña porción de la UG4 de Puerto Norte, la misma no registraba obras completas ni en ejecución a la fecha del censo 2010; por lo tanto, se puede suponer que todos los cambios socio demográficos ocurridos en este radio 02 tuvieron lugar en su porción correspondiente al barrio Refinería.

Ahora bien, los tres radios restantes (01, 06 y 09) comprenden al mismo tiempo partes de Refinería y sectores residenciales contiguos que no pertenecen al barrio propiamente dicho. Esto no debería representar un problema pues a efectos puramente prácticos, estas zonas linderas podrían considerarse parte de Refinería, o al menos, expuestas a las mismas presiones gentrificadoras. Los radios 01 y 09 son los más extensos y comprenden, además, la totalidad del área correspondiente a las Fases 1 y 2 de del GPU Puerto Norte. Esto tampoco debería representar un problema en el caso del radio 01 , pues ninguno de los nuevos desarrollos residenciales se hallaba completo a la fecha del censo.

El caso del radio 09 es diferente y complejo por dos motivos. Por un lado, al realizarse el censo de 2010 ya existía una ocupación parcial de algunos condominios y torres de vivienda correspondientes tanto a la Fase 1 como a la Fase 2. Por otro lado, existe un pequeño asentamiento informal localizado al norte de la rotonda, que no existía en 2001 y al que no correspondería considerar - al menos metodológicamente - como parte del barrio Refinería. En ambos casos es evidente la imposibilidad de determinar que porción de los cambios socio demográficos registrados por el censo ocurrieron específicamente en su parte correspondiente al barrio Refinería, cuáles en áreas residenciales linderas y cuáles dentro del área de Puerto Norte. Esta cuestión deberá ser tenida en cuenta antes de realizar cualquier interpretación específica acerca de este radio 09. 


\section{Derivaciones del gran proyecto Puerto Norte en el barrio Refinería ... /G. M. RODRÍGUEZ y B. CUENYA}

Ahora sí, de acuerdo a los parámetros fijados por el índice podemos afirmar que el barrio Refinería en conjunto califica como zona de presumible gentrificación. Los hogares de NSB que representaban 54.2 por ciento en 2001 pasaron a representar 39.7 por ciento nueve años más tarde, una importante reducción de 14.5 puntos porcentuales, bastante superior a 11.5 de Rosario. Esta perspectiva se ve confirmada por la fuerte disminución de hogares NSB en el barrio: -21.4 por ciento, es decir, 8.6 veces la disminución media verificada en el conjunto de la ciudad. Los hogares de NSA pasaron a ser mayoría, registrando un aumento de 41.5 por ciento, superando ampliamente el umbral de diez por ciento fijado al construir el índice.

Un análisis a nivel desagregado por radios censales permite observar algunas particularidades al interior del barrio. Califican como presumiblemente gentrificados los cuatro radios directamente limítrofes con el área de Puerto Norte. En todos estos radios el porcentaje de hogares NSB era superior a 51 por ciento en 2001 e inferior a 49 por ciento en 2010, con brechas que superan los 11.5 puntos porcentuales. Se destaca el radio 04, ubicado en el centro del barrio Refinería y que al sur limita con el nuevo centro comercial; allí se registró una disminución de hogares NSB de 21 puntos porcentuales dando lugar a un IVR de 14.9.

En el otro extremo, no llegan a calificar como gentrificados los dos radios más alejados hacia el oeste $(05$ y 06$)$, donde a pesar de haber sido fuerte la disminución de hogares NSB, el grupo NSB no era mayoritario en 2001 (no se cumple la condición 1). Tampoco califica como gentrificado el radio 09, principalmente en virtud de que su IVR de hogares NSB — si bien supera al de la ciudad - es inferior al valor de cinco fijado como umbral (no se cumple la condición 2). Recordemos sin embargo la situación particular de este extenso radio, donde se mezclan antiguos y nuevos pobladores de Refinería, con los nuevos pobladores de NSB del asentamiento precario y nuevos habitantes de NSA del sector de Puerto Norte (Tabla 3).

Con respecto a los tres indicadores sociodemográficos complementarios que presentamos como vinculados a los procesos de gentrificación se observa lo siguiente.

El indicador "régimen de tenencia" nuestra entre 2001 y 2010 una evolución poco compatible con la de un proceso de gentrificación (Tabla 4). La cantidad de propietarios (que en Rosario creció 11 por ciento) aumentó apenas 2.2 por ciento en Refinería (IVR 0.20) pasando de representar 73.4 por ciento en 2001 a 70.2 por ciento en 2010 . 


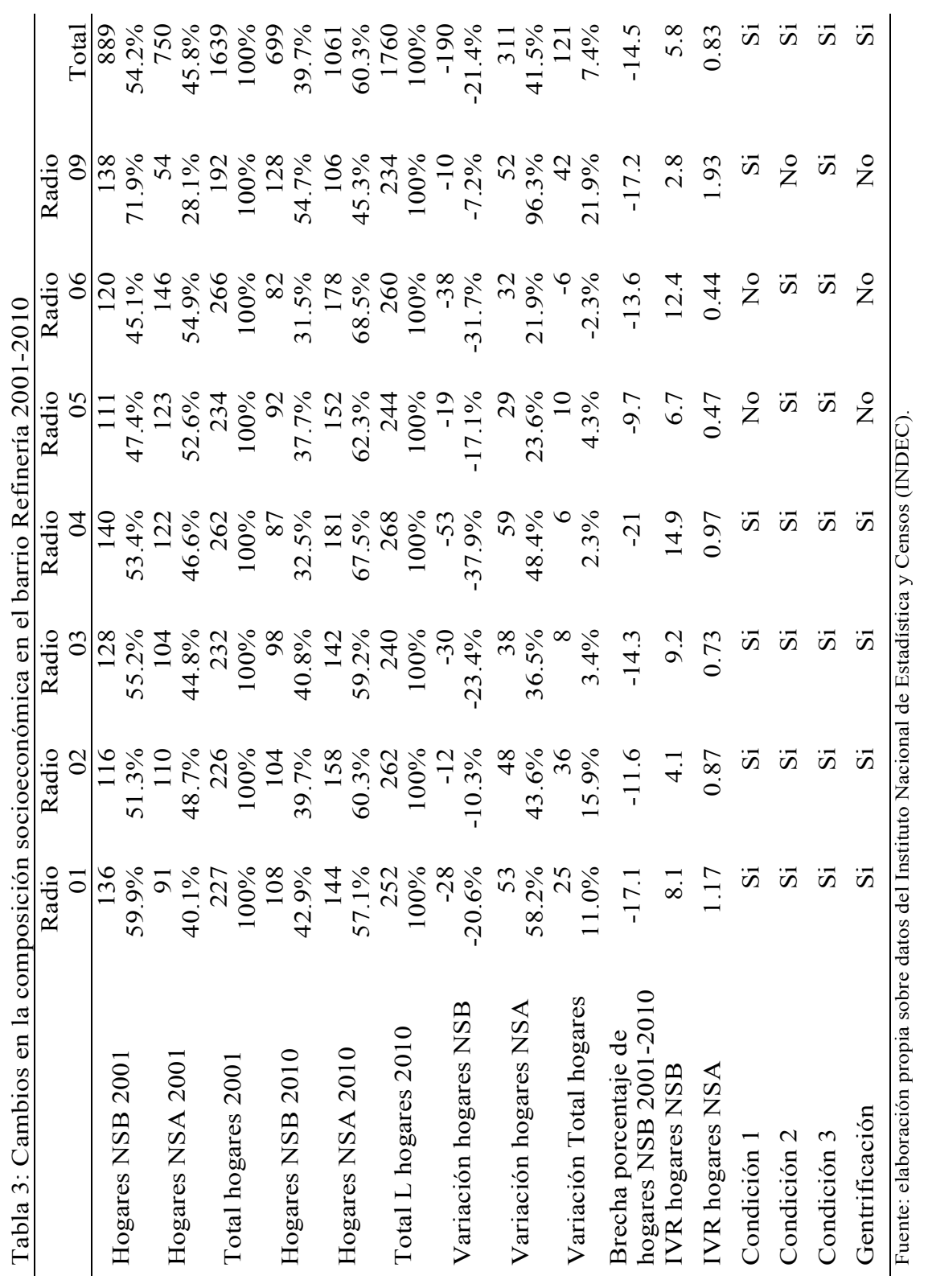


Derivaciones del gran proyecto Puerto Norte en el barrio Refinería ... /G. M. RODRÍGUEZ y B. CUENYA

Tabla 4: Cambios en el régimen de tenencia en el barrio Refinería 2001-2010

\begin{tabular}{|c|c|c|c|c|c|c|c|c|}
\hline & Radio & Radio & Radio & Radio & Radio & Radio & Radio & Refinería \\
\hline \multirow{3}{*}{ Propietarios 2001} & 169 & 139 & 180 & 209 & 189 & 200 & 108 & 1196 \\
\hline & & & & & & & & \\
\hline & $74 \%$ & $62 \%$ & $78 \%$ & $80 \%$ & $81 \%$ & $76 \%$ & $59 \%$ & $73.4 \%$ \\
\hline \multirow{2}{*}{ Inquilinos 2001} & 25 & 53 & 39 & 36 & 25 & 44 & 24 & 246 \\
\hline & $11 \%$ & $23 \%$ & $17 \%$ & $14 \%$ & $11 \%$ & $17 \%$ & $13 \%$ & $15.1 \%$ \\
\hline \multirow{2}{*}{ Otros 2001} & 33 & 34 & 13 & 17 & 20 & 20 & 50 & 187 \\
\hline & $13 \%$ & $14 \%$ & $6 \%$ & $6 \%$ & $8 \%$ & $7 \%$ & $27 \%$ & $11.5 \%$ \\
\hline \multirow{2}{*}{ Total hogares 2001} & 227 & 226 & 232 & 262 & 234 & 266 & 182 & 1629 \\
\hline & $100 \%$ & $100 \%$ & $100 \%$ & $100 \%$ & $100 \%$ & $100 \%$ & $100 \%$ & $100 \%$ \\
\hline \multirow{2}{*}{ Propietarios 2010} & 177 & 150 & 178 & 200 & 186 & 188 & 143 & 1222 \\
\hline & $70 \%$ & $57 \%$ & $74 \%$ & $75 \%$ & $76 \%$ & $72 \%$ & $67 \%$ & $70.2 \%$ \\
\hline \multirow{2}{*}{ Inquilinos 2010} & 33 & 79 & 50 & 51 & 45 & 57 & 29 & 344 \\
\hline & $13 \%$ & $30 \%$ & $21 \%$ & $19 \%$ & $18 \%$ & $22 \%$ & $14 \%$ & $19.8 \%$ \\
\hline \multirow{2}{*}{ Otros 2010} & 42 & 34 & 12 & 17 & 13 & 16 & 40 & 174 \\
\hline & $16 \%$ & $12 \%$ & $5 \%$ & $6 \%$ & $5 \%$ & $6 \%$ & $19 \%$ & $10.0 \%$ \\
\hline \multirow{2}{*}{ Total hogares 2010} & 252 & 263 & 240 & 268 & 244 & 261 & 212 & 1740 \\
\hline & $100 \%$ & $100 \%$ & $100 \%$ & $100 \%$ & $100 \%$ & $100 \%$ & $100 \%$ & $100 \%$ \\
\hline \multirow{2}{*}{$\begin{array}{l}\text { Variación propietarios } \\
(\text { ciudad }+11 \%)\end{array}$} & 8 & 11 & -2 & -9 & -3 & -14 & 35 & 26 \\
\hline & $5 \%$ & $8 \%$ & $-1 \%$ & $-4 \%$ & $-2 \%$ & $-7 \%$ & $32 \%$ & $2.2 \%$ \\
\hline \multirow{2}{*}{$\begin{array}{l}\text { Variación inquilinos } \\
\text { (ciudad }+69 \% \text { ) }\end{array}$} & 8 & 26 & 11 & 15 & 20 & 13 & 5 & 98 \\
\hline & $32 \%$ & $49 \%$ & $28 \%$ & $42 \%$ & $80 \%$ & $30 \%$ & $21 \%$ & $39.8 \%$ \\
\hline \multirow{2}{*}{$\begin{array}{l}\text { Variación otros } \\
(\text { ciudad }+34 \%)\end{array}$} & 12 & -1 & -2 & 2 & -6 & -3 & -10 & -8 \\
\hline & $41 \%$ & $-3 \%$ & $-15 \%$ & $13 \%$ & $-32 \%$ & $-16 \%$ & $-20 \%$ & $-4.3 \%$ \\
\hline IVR Propietarios $\left({ }^{*}\right)$ & 0.41 & 0.69 & -0.1 & -0.38 & -0.14 & -0.61 & 2.95 & 0.20 \\
\hline IVR Inquilinos $(*)$ & 0.46 & 0.71 & 0.41 & 0.6 & 1.15 & 0.43 & 0.30 & 0.58 \\
\hline IVR Otros & 1.21 & -0.09 & -0.44 & 0.38 & -0.94 & -0.47 & -0.59 & -0.13 \\
\hline Gentrificación & No & No & No & No & No & No & $\mathrm{Si}$ & No \\
\hline
\end{tabular}

El aumento más fuerte (cercano al 40 por ciento) se dio en la categoría inquilinos, que representaban 15 por ciento en 2001 y casi 20 por ciento diez años después. Con todo, y dado que este aumento de los inquilinos fue menor al de la ciudad (IVR 0.58) podría hablarse de una compatibilidad parcial con la evolución esperada de un proceso de gentrificación. 
En cuanto al tamaño de los hogares (Tabla 5) este indicador tampoco aporta evidencias claras de una gentrificación que se expresaría mediante una reducción de su tamaño promedio. Si bien es cierto que el promedio de miembros por hogar se redujo en Refinería, lo hizo con una intensidad menor a la de la ciudad en su conjunto. La única excepción es el radio 02, donde la disminución sí fue superior a la media de Rosario (IVR =1.39).

Por último, la edad promedio de los jefes de hogar es el único de los tres indicadores demográficos complementarios que ha mostrado signos compatibles con un proceso de gentrificación en el conjunto de Refinería (Tabla 6). La edad media de los jefes de hogar se redujo de 55.9 a 54.0 años, resultando en un índice de variación relativa de 1.47 puntos en relación a la disminución observada en Gran Rosario.

En síntesis, el conjunto del barrio Refinería muestra indicios positivos de gentrificación en sólo uno de los tres indicadores complementarios (disminución de la edad promedio de los jefes de hogar). A nivel desagregado, el radio 02 es el único —entre los identificados por nuestro índice como presumiblemente gentrificados- que cumple con dos de los tres indicadores. Los restantes radios cumplen con apenas uno o ningún indicador.

\section{EVIDENCIAS DE GENTRIFICACION EN REFINERIA: ESTUDIO DE CAMPO}

En vistas a completar los análisis anteriores, se examina a continuación cómo evolucionó otro conjunto de indicadores de gentrificación referidos al sector de la construcción, mercado inmobiliario y usos del suelo en el barrio Refinería. Los análisis surgen de un estudio de campo previo basado en observaciones de campo e información relevada de diversas fuentes secundarias (no censales) durante el año 2008.

\section{Cambios en los usos del suelo y renovación edilicia}

A través de recorridos y registros fotográficos se pudo observar que todavía para fines de 2008 el barrio Refinería se visualizaba como un tejido urbano y social modesto, conviviendo residencias (ampliamente predominantes) con depósitos medianos y algunas plantas industriales. Apenas se percibía un proceso muy incipiente de aparición de nuevos usos y servicios. Por ejemplo, estaba en proceso de instalación una empresa de servicios de catering destinada a atender, entre otros clientes, al centro comercial Alto Rosario. Pudimos saber también que algunas empresas de servicios se encontraban analizando la posibilidad de radicar a su personal en casas a reciclar en el lugar. 


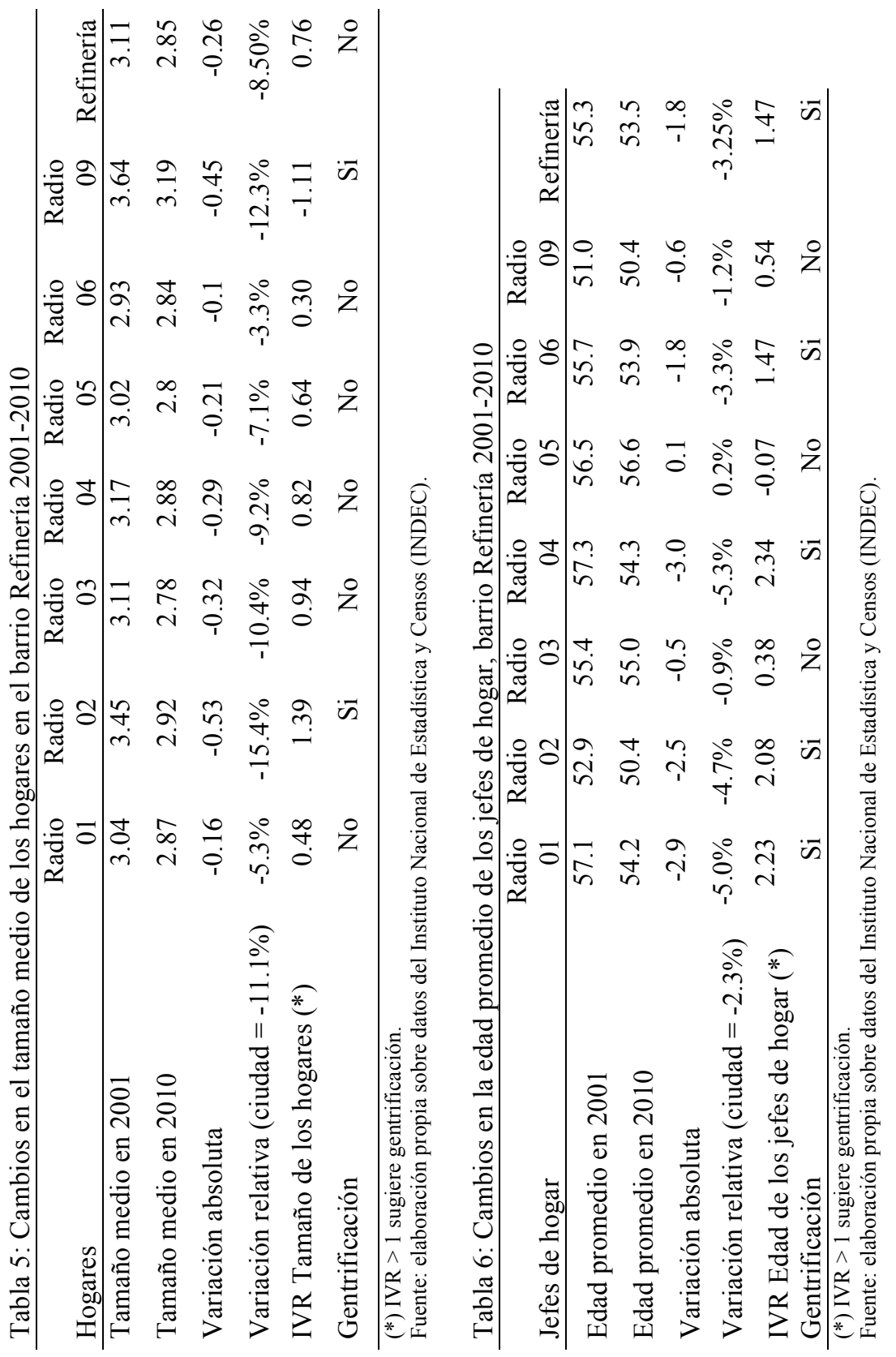


Además, se pudo comprobar la existencia de inversores interesados en la construcción de playas de estacionamiento, anticipando un futuro déficit que se produciría al completarse los emprendimientos de la primera fase de Scalabrini Ortiz. Si bien el grado de concreción era bajo, existían indicios de una posible tendencia a la radicación de empresas de servicios aprovechando la cercanía a los nuevos centros de consumo con alto poder adquisitivo. También en las arterias del borde del distrito contiguas a las obras de Puerto Norte se individualizaron, dispersos, tres pequeños lotes con oferta de servicios gastronómicos que anunciarían el inicio de un proceso de cambio más generalizado, pero que todavía no era visible.

El análisis de los movimientos de obras civiles en el barrio durante los cuatro años transcurridos entre mayo de 2004 hasta abril de 2008 permitió corroborar que fue limitada la renovación edilicia general en el barrio y que los emprendimientos de renovación urbana de Scalabrini Ortiz todavía no habían tenido un impacto significativo.

Por reglamentación municipal en Rosario toda demolición u obra civil debe solicitar un permiso de obra. En oportunidad del estudio se dispuso de la información de los 25 registros de permisos de obra presentados en la Dirección de Obras Civiles de la Municipalidad de Rosario para los años 2004, 2005, 2006 y 2007. La información fue validada con la base catastral de parcelas y georreferenciada, lo que permitió añadir a los registros la ubicación y superficie de las parcelas contenidas en los archivos. En la Tabla 7 se aprecia que la evolución de los permisos de obra y la superficie involucrada ha sido bastante limitada, teniendo en cuenta las 100 hectáreas que ocupa el barrio.

Tabla 7: Permisos de Obra y superficie en el Barrio Refinería, 2004-2007

\begin{tabular}{lrrr}
\hline & $2004 / 05$ & $2006 / 07$ & Total \\
\hline Permisos & 12 & 17 & 29 \\
Superficie & 2640 & 2412 & 5052 \\
\hline
\end{tabular}

Fuente: elaboración propia en base a registros de permisos de Obras. Dirección de Obras Civiles, Municipalidad de Rosario.

Pese a la tendencia anterior, un hecho observable compatible con un proceso de renovación urbana está dado por el cambio en el tipo de permisos que se produce a partir de 2006 (un año después de aprobada la Ordenanza Básica para Puerto Norte). Mientras que antes del 2006 no se otorgaban permisos para obras nuevas sino sólo para ampliaciones, a partir de dicho año, comienzan a gestionarse principalmente obras nuevas y se incrementan las demoliciones. Según se pudo averiguar, en varios casos 


\section{Derivaciones del gran proyecto Puerto Norte en el barrio Refinería ... /G. M. RODRÍGUEZ y B. CUENYA}

involucran a parcelas continuas, lo que hace suponer un proceso de englobamiento de lotes para emprendimientos de mayor envergadura (Tabla 8).

Tabla 8: $\mathrm{M}^{2}$ de obra según tipo y uso futuro. Barrio Refinería, 2004-2007

\begin{tabular}{|c|c|c|c|c|c|}
\hline $\begin{array}{l}\text { Tipo de obra } \\
\text { por año }\end{array}$ & $\begin{array}{r}2004 / 05 \\
\text { Obra nueva } \\
\end{array}$ & $\begin{array}{r}2004 / 05 \\
\text { Ampliación } \\
\end{array}$ & $\begin{array}{r}2006 / 07 \\
\text { Obra nueva } \\
\end{array}$ & $\begin{array}{r}2006 / 07 \\
\text { Ampliación } \\
\end{array}$ & Total \\
\hline Vivienda unifamiliar & 0 & 459 & 1211 & 191 & $\begin{array}{l}1861 \\
45 \%\end{array}$ \\
\hline Vivienda colectiva & 0 & 816 & 150 & 42 & $\begin{array}{l}1008 \\
24 \%\end{array}$ \\
\hline Comercio & 0 & 506 & 477 & 0 & $\begin{array}{r}983 \\
24 \%\end{array}$ \\
\hline Recreación & 0 & 135 & 0 & 0 & $\begin{array}{l}135 \\
3 \%\end{array}$ \\
\hline Depósito/industria & 0 & 149 & 0 & 0 & $\begin{array}{r}149 \\
4 \%\end{array}$ \\
\hline Total & 0 & 2065 & 1838 & 233 & $\begin{array}{r}4136 \\
100 \% \\
\end{array}$ \\
\hline
\end{tabular}

Fuente: elaboración propia en base a registros de permisos de Obras. Dirección de Obras Civiles, Municipalidad de Rosario.

\section{Cambios en los precios del suelo}

Durante el mes de noviembre de 2008 se relevaron los precios de oferta de terrenos en el barrio Refinería con el propósito de confrontarlos con los de marzo 2004 y así detectar el posible impacto del desarrollo urbano incipiente de Puerto Norte. En visitas a la ciudad de Rosario se accedió a inmobiliarias de la zona y se identificaron las propiedades a la venta. La información obtenida revela que en el barrio Refinería el precio por metro cuadrado se ofrecía en 2008 a un valor promedio de u\$s 400, con un piso de u\$s 300 y un máximo de u\$s 500. Estos precios están muy por encima de los verificados en 2004, cuando rondaban los u\$s 80 y u $\$$ s $150 \mathrm{el} \mathrm{m}^{2}$.

Sin embargo el encarecimiento del suelo se debe sólo en parte a los cambios edilicios y de usos del suelo producidos en el barrio ya que, como se vio, éstos fueron acotados durante el periodo. Antes bien, es posible que expresen las expectativas por las transformaciones urbanísticas en el entorno (especialmente Puerto Norte) así como también el movimiento general de precios de las propiedades en Rosario, donde por ejemplo, el valor del $\mathrm{m}^{2}$ de departamentos usados en el casco urbano rosarino pasó de u\$s 353 en 2003 a u\$s 900 en 2008. 
Otro aspecto que corrobora el componente de expectativa en los precios en el barrio es la mayor extensión del tiempo en el que las propiedades permanecen en venta, así como la permanencia de proyectos inmobiliarios que no terminan de concretarse. La situación varía según la mayor o menor proximidad con las nuevas obras ya concretadas. Por ejemplo, la oferta de terrenos y de los escasos departamentos a estrenar es mayor a medida que nos acercamos a la UG5 (cuyas obras ya se encontraban avanzadas para 2008) y al centro comercial Alto Rosario, en cuya proximidad ya en 2004 comenzaban a evidenciarse ciertas mejoras en estos terrenos respecto a los más alejados.

\section{Conclusiones}

En términos estrictamente estadísticos y a partir del índice desarrollado en este trabajo hemos encontrado sugestivas evidencias de gentrificación en el barrio Refinería entre 2001 y 2010. En la medida que estos cambios en la composición socioeconómica del barrio difícilmente puedan ser atribuidos exclusivamente a la mejora general en el nivel educativo de los jefes de hogar que se registró en el conjunto de Rosario, estaríamos en condiciones de afirmar que Refinería ha experimentado un proceso de gentrificación, cuando menos leve e incipiente.

Otros indicadores estadísticos complementarios observados en el Barrio Refinería sugieren evidencias contradictorias y parciales de gentrificación. Sólo la edad promedio de los jefes de hogar ha disminuido más que en el conjunto urbano, hecho compatible con un proceso de gentrificación; no así los indicadores de régimen de tenencia y cantidad de miembros del hogar, que mostraron movimientos no compatibles con los esperados en este tipo de procesos de acuerdo a la literatura especializada. No puede sin embargo concluirse a partir de este trabajo si su pertinencia como indicadores válidos de gentrificación debe ser revisada en función de las especificidades del caso de estudio.

Retomando nuestro índice, hemos hallado que las evidencias de posible gentrificación se extienden más allá del barrio Refinería, replicándose en un total de 109 radios censales que representan aproximadamente diez por ciento de los radios en que se subdivide la aglomeración Gran Rosario. Es interesante notar que ninguno de estos radios presumiblemente gentrificados se localizan en el área central, sino mayormente en los bordes de esta área central y otros subcentros en la periferia. Pareciera ser principalmente allí, en estas zonas intermedias entre el centro y la periferia (entre ellas el Barrio Refinería) donde actualmente se desarrolla una gentrificación "si- 
lenciosa" o "a cuentagotas", no necesariamente vinculada a grandes proyectos de renovación urbana como Puerto Norte.

Un comentario especial merece lo sucedido en el área central de Rosario. Aunque ninguno de los radios censales que integran el área califica como zona gentrificada de acuerdo a nuestro índice (pues ninguno tenía mayoría de hogares NSB al comienzo del periodo) la disminución relativa de hogares NSB ha sido allí muy intensa. Esto sugiere que si el área central de Rosario presentaba cierto grado de mixidad a comienzos de la década de 2000, su composición socioeconómica se estaría volviendo cada vez más exclusiva. También es posible que estemos en presencia de un proceso de gentrificación en estado avanzado, el cual sólo podría revelarse si extendiéramos el periodo de análisis una década hacia atrás (1991-2010).

Los estudios de campo realizados en Refinería basados tanto en la observación in situ como en entrevistas y recopilación de fuentes cuantitativas complementarias (no censales) sugieren un panorama similar al anterior. Para fines de 2008 no se observaban todavía rasgos fuertes y unívocos de gentrificación. Indicadores como subas generalizadas en los precios del suelo, cambios en el patrón de usos, renovación del stock edilicio y construcción de nuevos inmuebles, todos mostraron mutaciones bastante acotadas. En 2008 los precios en Refinería registraban un aumento de entre dos y tres veces por encima de los observados en 2004. Se trató, sin embargo, de una oferta conformada más que nada con precios de expectativa, sin correspondencia con una presión de la demanda. Por otro lado, dicha suba en los precios del suelo tampoco difiere del nivel generalizado de subas registrado en el conjunto de Rosario. También se observó una notable extensión de los plazos en los cuales las propiedades permanecían en venta y de proyectos inmobiliarios que no terminaban de concretarse.

Con respecto a los usos del suelo y en la calidad de edificación, los recorridos realizados en el barrio no revelaron cambios notables en la configuración histórica del barrio, caracterizada por su tejido urbano modesto, mixturado con viviendas, depósitos medianos y algunas plantas industriales. Sí se percibió, en cambio, un proceso incipiente de aparición de nuevos usos y servicios, vinculados al Centro Comercial Alto Rosario construido en la primera etapa de Puerto Norte.

El cambio más sugestivo observado y que podría ser un indicador de un proceso acotado de llegada de residentes de mayores ingresos al barrio se refiere a la modificación en el tipo de permisos que se produce a partir de 2006. Mientras que antes del 2006 no se otorgaban permisos para obras nuevas sino sólo para ampliaciones, a partir de dicho año, se gestionan 
principalmente obras nuevas, se incrementan las demoliciones y el englobamiento de parcelas para emprendimientos de mayor envergadura.

Ahora bien ¿qué razones podrían explicar el alcance limitado de las transformaciones urbanas y socioeconómicas ocurridas en Refinería?

En primer lugar, la baja en los indicadores de aprovechamiento edilicio introducidos por la Ordenanza 7892/05. Atendiendo a la idea original del municipio, esta normativa pudo haber operado efectivamente como un freno al avance de inversiones inmobiliarias de cierta envergadura, como la construcción en altura de nuevos edificios residenciales, comerciales o de oficinas. Se habría cumplido así el objetivo del gobierno municipal de mantener el perfil del barrio y evitar o al menos contener su gentrificación.

En segundo lugar, también es posible hipotetizar que el grueso de la población del barrio Refinería no constituye un grupo social propenso a cambiar la localización de sus residencia, teniendo en cuenta que el barrio posee una buena infraestructura domiciliaria, servicios y comercios calificados, además de buena conectividad urbana y accesibilidad al área central. Aunque podría no ser el caso del conjunto de pequeños propietarios localizados en el área incorporada al perímetro de Puerto Norte (como Unidad de Gestión 4), el que sí podría representar un grupo social más vulnerable a las presiones del mercado inmobiliario dada su mayor vecindad a los nuevos desarrollos urbanos.

Finalmente $-\mathrm{y}$ sin detrimento de las hipótesis anteriores - es posible pensar que aún es escaso el tiempo transcurrido desde la finalización de una parte de los nuevos emprendimientos. Más allá del importante grado de avances de las obras, Puerto Norte estaba lejos de haberse completado, tanto al realizarse nuestro estudio de campo en 2008, como al realizarse el censo de 2010. ${ }^{14}$ Puede ocurrir que con la culminación total de las obras y finalmente con la ocupación completa y puesta en funcionamiento de todo el sector Puerto Norte, se intensifique la presión gentrificadora sobre el Barrio Refinería y se manifiesten más nítidamente sus impactos. Futuros estudios con nuevos datos actualizados podrán dar mejor cuenta de estos procesos que, como la gentrificación, se desarrollan a lo largo del tiempo.

\footnotetext{
${ }^{14}$ Tampoco lo estaba en 2015, cuando parte de nuestro equipo realizó una breve visita a Puerto Norte y Refinería. Con la mayor parte de las obras ya completadas, el nivel de ocupación efectiva del nuevo parque inmobiliario parecía bastante bajo. Tampoco se observaron mayores cambios al interior del barrio Refinería respecto a los ya comentados.
} 


\section{REFERENCIAS BIBLIOGRAFICAS}

Barenboim, C. A., 2013, Mercado inmobiliario, normativa e impacto territorial. Rosario y su periferia. Universidad Nacional de Rosario.

Butler, T. y Lees, L., 2006, "Super-gentrification in Barnsbury, London: globalization and gentrifying global elites at the neighbourhood level", en Transactions of the Institute of British Geographers, vol. 31, núm. 4, p. 467-487.

Cuenya, B., González, E.; Mosto, G. y Pupareli, S., 2009, Movilización de plusvalias en un gran proyecto urbano. La experiencia de Puerto Norte en la ciudad de Rosario, Argentina. Informe Final de Investigacion, Lincoln Institute of Land Policy.

Cuenya, B., 2006, “Grandes proyectos como herramientas de creación y captación de plusvalías urbanas. Proyecto Puerto Norte, Rosario”, en Medio Ambiente y Urbanización, núm. 6, p. 81-108, IIED-AL, Buenos Aires.

Cuenya, B., 2012, "El impacto social de los grandes proyectos urbanos: la gentrificación. Balance preliminar del estado de conocimiento sobre el tema", Presentado al seminario Mega Events, Mega Projects and Urban Democracy. CEUR, Buenos Aires 30 y 31 de agosto.

Glass, R., 1964, London: aspects of change. Londres: MacGibbon and Kee.

Hamnett, Ch., 2003, "Gentrification and the Middle-class Remeaking of Inner London, 1961-2001”, en Urban Studies, vol. 40, núm. 12, 2401-2426

Herzer, H. M., 2008, “Acerca de la gentrificació”, en Herzer, H (ed.) Con el corazón mirando al sur - Transformaciones en el sur de la ciudad de Buenos Aires, p. 19-44. Buenos Aires: Espacio Editorial.

Kozak, D. y Feld, N., 2015, "La llegada al río a través de un macro proyecto urbano: estudios sobre el espacio público costero en Puerto Norte en la ciudad de Rosario, Argentina", II Congreso Latinoamericano de Estudios Urbanos. Facultad de Arquitectura, Universidad Nacional Autónoma de México, México, 18-20 de mayo.

Ley, D., 1986, “Alternative explanations for inner-city gentrification: a Canadian assessment", en Annals of the Association of American Geographers, vol. 76, núm. 4, p. 521-535.

Rubiales Pérez, M., 2014, “Medir la gentrificación? Epistemologías, metodologías y herramientas de investigación de carácter cuantitativo y mixto", en Contested Cities.

Sandroni, P., 2006, "Renovación urbana y gentrificación: evaluación de algunos impactos demográficos, sociales y económicos de la operación urbana Faría Lima en la ciudad de San Pablo", en Medio Ambiente y Urbanización, núm. 65, p. 109116. IIEDAL, Buenos Aires.

Schaffer, R. y Smith, N., 1986, "The Gentrification of Harlem?”, en Annals of the Association of American Geographers, vol.76, núm. 3, p. 347-365. 
Slater, T., 2006, "The eviction of critical perspectives from gentrification research", en International Journal of Urban and Regional Research, vol. 30, núm. 4, p. 737-757.

\section{RESUMEN CURRICULAR DE LOS AUTORES}

\section{Gonzalo Martin Rodríguez}

Es Doctor en Ciencias Sociales por la Universidad de Buenos Aires (UBA), Argentina, Licenciado en Sociología (UBA) y Magíster en Planificación Urbana y Regional por la misma universidad. Se desempeña como investigador Adjunto en el Centro de Estudios Urbanos y Regionales (CEUR) del Consejo Nacional de Investigaciones Científicas y Técnicas (CONICET). Se especializa en temáticas de segregación residencial, gentrificación, Grandes Proyectos Urbanos (GPU) y su estudio cuantitativo a partir de información y cartografía censal.

Dirección electrónica: gonzalor@conicet.gov.ar

\section{Beatriz Cuenya}

Es Doctora en Urbanismo por la Delft University of Technology, Holanda. Egresó como Arquitecta de la Universidad Nacional de Tucumán, Argentina y realizó estudios de postgrado en Desarrollo Urbano y Regional en el Instituto Torcuato Di Tella, en Buenos Aires. Es Directora e Investigadora del Centro de Estudios Urbanos y Regionales (CEUR) del Consejo Nacional de Investigaciones Científicas y Técnicas (CONICET). Ha integrado en varios períodos la Comisión Asesora de Hábitat del CONICET. Fue Profesora en la Maestría de Políticas Sociales Urbanas de la UNTREF. Ha dirigido proyectos y equipos de investigación y ha publicado numerosos trabajos sobre asentamientos populares, política de vivienda y desarrollo urbano. En los últimos años sus investigaciones y publicaciones se vinculan con la problemática de los Grandes proyectos urbanos y la gestión del suelo. Ha co-coordinado un proyecto de cooperación internacional sobre ese tema, con el Programa Universitario de Estudios sobre la Ciudad de la Universidad Nacional Autónoma de México (PUEC-UNAM).

Dirección electrónica: beatrizcuenya@conicet.gov.ar 